\title{
Larvicidal Activity against the Cabbage Webworm, Hellula undalis (Fabricius) (Lepidoptera: Pyralidae) of the Extract from Pongam Leaves (Pongamia pinnata L.)
}

\author{
D.H. Tran, T.G. Nguyen, T.X.P. Tran, T.H.D. Tran
}

10.18805/LRF-669

\begin{abstract}
Background: The cabbage webworm, Hellula undalis (Fabricius) (Lepidoptera: Pyralidae) is destroy insect pest in vegetable crops. Vegetable growers spray many kinds of chemical pesticides to control this insect pest. The objective of this study was to investigate the efficacy of the extract from pongam leaves, Progamia pinnata L. against the cabbage webworm.

Methods: The experiment was carried out at the Laboratoty of Entomology, Faculty of Agronomy, University of Agriculture and Forestry, Hue University, Vietnam during 2020 and 2021. Different concentrations of pongam leaf extract was tested its efficacy against first and second instar larvae of the cabbage webworm on potted plants of leaf mustard, Brassica integrifolia West.

Result: The efficacy of pongam leaf extract was more efficacious against the first instar than the second instar of $H$. undalis. At five days after treatment, the efficacy of the pongam leaf extract against first and second instars of $H$. undalis was 93.2 and $68.4 \%$ at concentrations of $1.0 \%$, respectively. Therefore, the pongam leaf extract can be recommended as potential botanical insect ides to control the cabbage webworm.
\end{abstract}

Key words: Cabbage, Hellula undalis, Botanical insecticide, Leaf extract, Pongam.

\section{INTRODUCTION}

The cabbage webworm, Hellula undalis (Fabricius) (Lepidoptera: Pyralidae) was destroy insect pest in vegetable in the world (Waterhouse and Norris, 1989). Previous studies reported its serious damage in Malaysia (Sivapragasan and Chua, 1997), India (Dhawan and Matharu, 2011), Vietnam (Tran et al., 2019). Larvae of the cabbage webworm damage plant leaves and stems. They make a silk web around their damage area. Its damage can cause either plant death or production which are not marketable (Sivapragasan, 2005). Vegetable growers applied many kinds of chemical pesticides to control the cabbage webworm (Tran et al., 2018). However, over applying of chemical pesticides caused negative impact to human, environment and benefit species (Tran et al., 2004; Tran and Ueno, 2012). Insects can develop their resistance to insecticides if farmers continuously use of the chemicals, thus efficacy of the insecticides is decreased its efficacy. Therefore, people have to increase the dosage and frequency of use leads to increased costs, increased pesticide residues in agricultural product, soil and water (Nguyen et al., 2018).

Botanical pesticides have been used as potential alternatives synthetic pesticides because the natural products would cause lesser impact on environmental and human health than many conventional chemical pesticides (Isman et al., 2011). Erler et al. (2010) reported that many species of plants have been used as botanical pesticides to control target pests. Previous studies indicated high effectiveness of plant extract in insect pests control (Mamun et al., 2009; Gupta and Srivastav, 2008; Dharanipriya and
University of Agriculture and Forestry, Hue University 102 Phung Hung Street, Hue City, Vietnam.

Corresponding Author: D.H. Tran, University of Agriculture and Forestry, Hue University 102 Phung Hung Street, Hue City, Vietnam. Email: tdanghoa@hueuni.edu.vn

How to cite this article: Tran, D.H., Nguyen, T.G., Tran, T.X.P. and Tran, T.H.D. (2022). Larvicidal Activity against the Cabbage Webworm, Hellula undalis (Fabricius) (Lepidoptera: Pyralidae) of the Extract from Pongam Leaves (Pongamia pinnata L.). Legume Research. DOI: $10.18805 /$ LRF-669.

Submitted: 19-11-2021 Accepted: 22-01-2022 Online: 03-03-2022

Kannan, 2020; Shunmugadevi and Anbu Radhika, 2020; Nasrin et al., 2021).

Pongam trees, Progamia pinnata L., belonging to the family Fabacae was widely distributed in many Asian countries including India, the Philippines, Malaysia, Indonesia and Vietnam (Atote and Yeole, 2010). It can planted on many type of soil and has low demand on humidity. Pongam trees have planted for agriculture and environment management. The various parts of pongam tree have been used for controlling of insect pests and diseases (Shoba and Thomas, 2001; Meera et al., 2003). The insecticidal feature of $P$. pinnanta have been widely tested (Kerasi et al., 2010). The leaf extract of pongam contain insecticidal feature against caterpillar insect pests such as the beet armyworm and the tobacco armyworm (Tran et al., 2017). The objectives of this study were to investigate laboratory efficacy of the extract from pongam leaves against larvae of the cabbage webworm. 


\section{MATERIALS AND METHODS}

The experiment was carried out at the Laboratoty of Entomology, Faculty of Agronomy, University of Agriculture and Forestry, Hue University, Viet Nam during 2020 and 2021 with different concentrations of pongam leaf extract against first and second instar larvae of the cabbage webworm on potted plants of leaf mustard, Brassica integrifolia West.

Seedlings of leaf mustard were separately planted in a plastic pot $(9 \mathrm{~cm} \times 10 \mathrm{~cm})$ contenting approximately $0.5 \mathrm{~kg}$ of a mixture soil. Properties of the potting soil was with $\mathrm{pH}=5.2$, $1.5 \%$ organic carbon and available content of $4.59 \mathrm{mg} \mathrm{K} \mathrm{K}_{2} \mathrm{O}$, $0.65 \mathrm{mg} \mathrm{N}$ and $10.5 \mathrm{mg} \mathrm{P}_{2} \mathrm{O}_{5}$ per $100 \mathrm{~g}$ of soil. Two weeks after planting, the potted plants were maintained in a chamber with $60-70 \%$ humidity, $30 \pm 1.0^{\circ} \mathrm{C}$ and $12 \mathrm{~L}$ : $12 \mathrm{D}$ photoperiod.

The cabbage webworm $(H$. undalis $)$ used for the present study were collected from leaf mustard fields at Thua Thien Hue province, Central Vietnam $\left(16^{\circ} 43^{\prime} 16.14 " \mathrm{~N}\right.$; $\left.107^{\circ} 71^{\prime} 56.29 " \mathrm{E}\right)$. The insects were reared on potted plants set inside a cage with the size of $60 \times 160 \times 180 \mathrm{~cm}$. The colony of $H$. undalis were established on the potted plants in an incubator ( $25 \pm 1^{\circ} \mathrm{C}$ and $12 \mathrm{~L}: 12 \mathrm{D}$ photoperiod). Using the larvae of $H$. undalis collected from the colony maintained on these plants for two to three generations in the experiments.

The leaves of $P$. pinnata were collected from the open fields at Thua Thien Hue Province, Vietnam. The collected leaves were washed under tap water in order to remove debris. Afterwards the clean leaves were placed in shade for air-drying and then dried in the oven at $60^{\circ} \mathrm{C}$ to gain a constant weight. The dried leaves were grinded and sieved through a 25 mesh sieve to collect fine powder. The powder was preserved in airtight condition in polythene bags till use in extract preparation. The powder was evenly packed in Soxhlet's apparatus and the extraction was done with methanol. The leaf extract was concentrated in vacuum evaporator and dried and then labeled and stored at $4^{\circ} \mathrm{C}$ in amber colored airtight bottles.

A stock solution of $200 \mathrm{ml}$ with a concentration of $5 \%$ leaf extract was prepared by diluting with Acetone 300, $99.5+\%$ (GC). The stock solution was dissolved in acetone to make tested concentrations until being equivalent to $0.6,0.7,0.8$, 0.9 and $1.0 \%$. The fluids were mixed with teepol of about $0.003 \mathrm{ml}$ or three drops from a needle tip were added to give the extracts a slightly sticky characteristic. The leaves of potted plants was sprayed with the leaf extract until runoff (approximately $5 \mathrm{ml}$ per a potted plant) using a power-pack aerosol hand sprayer (Hand Spray Nozzle, Takeda Engei Co., Japan).

Five first instar or second instar larvae collected from the laboratory colony of $H$. undalis and exposed to a potted plant after one hour spraying. The plant were replaced to a plastic cage $(10 \times 15 \times 20 \mathrm{~cm})$ covered with a fine nylon mesh. The potted plants as control was sprayed with distilled acetone in the same way as extract above. Twenty five larvae were tested each treatment. All plants were maintained in an incubator $\left(60-70 \%\right.$ humidity, $28 \pm 1.0^{\circ} \mathrm{C}$ and $12 \mathrm{~L}$ : $\left.12 \mathrm{D}\right)$. After 1,3 and 5 days treatment, larval mortality was counted.
Mortality of insects in the laboratory was calculated using the corrected formula of Abbott (1925). Percentage data was transformed into arcsine square root before analysis. Data was analyzed with Tukey-Kramer test after one way ANOVA by using STATISTICA 10.0 software.

\section{RESULTS AND DISCUSSION}

From the leaves of pongam tree, $P$. pinnata collected in Thua Thien Hue Province, Vietnam, five organic compounds belonging to the furanoflavone group were isolated and identified, including pongaglabrone, pongapinnatin, pongapin, pongamone D, gamatin (Nguyen et al., 2014). These compounds have larvicidal activity against insect pests (Ghosh, 2000). Our results showed that the extract from the leaves of pongam tree has significant larvicidal activity against young and older instars of the cabbage webworm, $H$. undalis. The efficacy was varied at different concentrations of the leaf extract and between first and second instars of the cabbage webworm. High concentrations of the pongam leaf extract caused higher mortality of $H$. undalis larvae.

At one day after treatment, the efficacy of the pongam leaf extract at the concentrations of 0.6 and $0.7 \%$ against the first instar larvae of $H$. undalis was not significantly difference $(P>0.05)$, ranging from 36.7 to $38.3 \%$. When increasing the concentration to $0.8 \%$, the efficacy was higher and no significantly difference between the concentrations of 0.6 and $0.7 \%(P<0.05)$. There was no significantly difference in the efficacy of the leaf extract at the concentrations of $0.8,0.9$ and $1.0 \%$, ranging from 46.7 to $51.7 \%$ (Table 1). The efficacy of the leaf extract increased with time after treatment. At three days after treatment, the efficacy was increased at all concentrations. There were no significantly difference in the efficacy at the concentration of $0.8,0.9,1.0 \%$ and higher than at the concentration of 0.6 and $0.7 \%(P>0.05)$. At five days after treatment, the highest efficacy was $93.2 \%$ at the concentration of $1.0 \%$. There was no significant difference in the efficacy at the concentrations of 0.9 and $0.8 \%(P>0.05)$.

Similar to the first instar larvae, all different concentrations of the pongam leaf extract were effective against the second instar larvae of the cabbage webworm. The efficacy of the pongam leaf extract was less efficacy against the second instar larvae than the first instar larvae of $H$. undalis and was according to the evaluation time (Table 2). At one day after treatment, the efficacy reached $20.0-35.6 \%$. There was significantly difference in the efficacy at concentrations of $0.8,0.9$ and $1.0 \%$ compared with those of the concentrations of 0.6 and $0.7 \%(P<0.05)$. The insecticidal efficacy gradually increased after tested time. At five days after treatment, the highest efficacy was $68.4 \%$ at the concentration of $1.0 \%$, followed by $60.0,61.0,53.8$ and $48.0 \%$ at the concentrations of $0.9,0.8,0.7$ and $0.6 \%$, respectively $(P<0.05)$ (Table 2$)$.

Many previous studies also reported that the pongam leaf extract were also high effctive against various lepidopteran insects such as the beet armyworm, Spodoptera exigua (Hübner) and the tobacco armyworm, Spodoptera litura 
Larvicidal Activity against the Cabbage Webworm, Hellula undalis (Fabricius) (Lepidoptera: Pyralidae) of the Extract from...

Table 1: Efficacy (\%) of different doses of pongram leaf extract on $H$. undalis first instar larvae.

\begin{tabular}{lccc}
\hline Concentration(\%) & $1 \mathrm{DAT}^{*}$ & $3 \mathrm{DAT}$ & $5 \mathrm{DAT}$ \\
\hline 0.6 & $36.7 \pm 2.11 \mathrm{~b}$ & $66.1 \pm 2.00 \mathrm{~b}$ & $79.3 \pm 0.47 \mathrm{c}$ \\
0.7 & $38.3 \pm 1.67 \mathrm{~b}$ & $72.8 \pm 2.34 \mathrm{~b}$ & $84.3 \pm 2.59 \mathrm{bc}$ \\
0.8 & $46.7 \pm 2.11 \mathrm{a}$ & $79.6 \pm 2.61 \mathrm{a}$ & $88.2 \pm 3.06 \mathrm{ab}$ \\
0.9 & $46.7 \pm 3.33 \mathrm{a}$ & $84.8 \pm 2.16 \mathrm{a}$ & $91.3 \pm 1.78 \mathrm{ab}$ \\
1.0 & $51.7 \pm 1.67 \mathrm{a}$ & $84.8 \pm 2.16 \mathrm{a}$ & $93.2 \pm 2.17 \mathrm{a}$ \\
$\mathrm{LSD}_{0,05}$ & 0.369 & 0.580 & 1.920 \\
\hline
\end{tabular}

Means with the same letters within the same column are not significantly different by one way ANOVA, $P<0.05$.

*DAT (days after treatment)

Table 2: Efficacy (\%) of different doses of pongram leaf extract on $H$. undalis second instar larvae.

\begin{tabular}{lccc}
\hline Concentration(\%) & $1 \mathrm{DAT}^{*}$ & $3 \mathrm{DAT}$ & $5 \mathrm{DAT}$ \\
\hline 0.6 & $20.0 \pm 2.36 \mathrm{~b}$ & $30.6 \pm 2.81 \mathrm{c}$ & $48.0 \pm 2.54 \mathrm{~d}$ \\
0.7 & $21.1 \pm 2.61 \mathrm{~b}$ & $34.0 \pm 3.19 \mathrm{c}$ & $53.8 \pm 2.94 \mathrm{~cd}$ \\
0.8 & $28.9 \pm 2.00 \mathrm{a}$ & $44.2 \pm 2.06 \mathrm{ab}$ & $61.0 \pm 2.79 \mathrm{~b}$ \\
0.9 & $30.0 \pm 2.36 \mathrm{a}$ & $43.0 \pm 2.39 \mathrm{~b}$ & $60.0 \pm 1.76 \mathrm{bc}$ \\
1.0 & $35.6 \pm 1.76 \mathrm{a}$ & $52.4 \pm 3.56 \mathrm{a}$ & $68.4 \pm 2.15 \mathrm{a}$ \\
LSD $_{0,05}$ & 0.581 & 0.728 & 0.532 \\
\hline
\end{tabular}

Means with the same letters within the same column are not significantly different by one way ANOVA, $P<0.05$.

*DAT (days after treatment)

Fabricius (Lepidoptera: Noctuidae) (Tran et al., 2017) and other insects such as the cotton aphis, Aphid gossypii (Glover) (Hemiptera: Aphididae), the cotton leaf hopper, Amrassca devasttans (Distant) (Hemiptera: Cicadellidae) (Kulat et al., 1997) and the turnip aphid, Lipaphis pseudobrassicae (Davis) (Heminoptera: Aphididae) (Tran et al., 2016). This study shown the pongam leaf extract was high larvicidal activity against the cabbage webworm, $H$. undalis. Larvicidal activities of the pongam leaf extracts can be also attributed to some organic compounds including karanjin and pongapin, the major flavonoid of the leaf extract (Asolkar et al., 1992; Katekhaye et al., 2012). Verma et al. (2011) reported that karanjin and pongapin had high insecticidal properties. Poonia and Kaushik (2013) also indicated a significant synergistic effect of the pongam leaf extract.

The pongam leaf extract also has sub-lethal effect such as antifreedant and repellent effects on many insect pests. Previous studies have demonstrated the antifeedant effect of pongam extracts on S. litura (Lepidoptera: Noctuidae), Trogoderma granarium Events (Coleoptera: Dermestidae) and Tribolium castaneum (Herbst) (Coleoptera: Tenebrionidae) (Kumar et al., 2006) and the repellent effect on mosquito (Lale and Kulkarni, 2010). This study was not tested on antifeedant or repellent effects, the previous studies provided evidence that low concentrations of the pongam leaf extract caused significantly reduction of population growth of the beet armyworm, the tobacco armyworm and and the turnip aphid (Tran et al., 2016; Tran et al., 2017).

\section{CONCLUSION}

The extract from pongam leaves, $P$. pinnata had high larvicidal activity against first instar and second instar larvae of the cabbage webworm, $H$. undalis. Applying plant extracts for pest management was less impact on environment, health and development of insect resistance to insecticides (Isman, 1995; Breuer et al., 2003). Charleston et al. (2006) indicated that plant extracts could attract more natural enemies. Therefore, the pongam leaf extract can be recommended as potential botanical insect ideas for being used together with biological control agents to control the cabbage webworm.

\section{ACKNOWLEDGEMENT}

The authors acknowledge the partial support of Hue University under the Core Research Program, Grant No. NCM.DHH.2020.14.

Conflict of interest: None.

\section{REFERENCES}

Abbott, W.S. (1925). A method of computing the effectiveness of an insecticide. Journal of Econnmic Entomology. 18: 265267.

Arote, S.R. and Yeole, P.G. (2010). Pongamia pinnata L.: A comprehensive review. International Journal of PharmTech Research. 2: 2283-2290.

Asolkar, L.V., Kakkar, K.K., Charkre, O.J. (1992). Glossary of Indian Medicinal Plants with Active Principles. Part I (A-K) (1965-1981). CSIR, New Delhi, India. pp. 265-266.

Breuer, M., Hoste, B., De Loof, A., Naqvi, S.N.H. (2003). Effect of Melia azedarach extract on the activity of NADPHcytochrome reductase and cholinesterase in insects. Pesticide Biochemistry and Physiology. 76: 99-103.

Dharanipriya, N. and Kannan, R. (2020). Investigations on the larvicidal effect of red algal seaweeds of rameswaram coast against tobaco caterpillar Spodoptera litura (Fab.). Indian Journal of Agricultural Research. 54: 181-186. 
Dhawan, A.K., Matharu K.S. (2011). Biology and morphometry of cabbage head borer, Hellula undalis Fab. (Pyralidae: Lepidoptera). Indian Journal of Applied Entomology. 25: 100-102.

Erler, F., Cetin, H., Saribasak, H., Sertas, A. (2010). Laboratory and field evaluation of some botanical pesticides against the cedar leaf moth, Acleris undulana. Journal of Pesticide Science. 83: 265-272.

Ghosh, G.K. (2000). Bio-pesticides and Integrated Pest Management. APH Publishing. pp. 286

Gupta, L. and Srivastava, M. (2008). Effect of Withania somnifera extracts on the mortality of Callosobruchus chinensis L. Journal of Biopesticides. 1: 190-192.

Isman M.B., Miresmailli, S., Machial, C. (2011). Commercial opportunities for pesticides based on plant essential oil in agriculture, industry and consumer products. Phytochemistry Reviews. 10: 197-204.

Isman, M.B. (1995). Leads and projects for the development of new botanical insecticides. Reviews in Pesticide Toxicology. 3: $1-20$.

Katekhaye, S., Kale, M.S., Landdha, K.S. (2012). Development and validation of and HPLC method for karanjin in Pongamia pinnata Linn. leaves. Indian Journal of Pharmaceutical Science. 74: 72-75.

Kesari, V., Das, A., Rangan, L. (2010). Physico-chemical characterization and antimicrobial activity from seed oil of Pongamia pinnata, a potential biofuel crop. Biomass and Bioenergy. 34: 108-115.

Kulat, S.S., Nimablkar, S.A., Hiwase, B.J. (1997). Relative efficacy of some plant extracts against Aphis gossypii (Glover) and Amrasca devastans (Distant) on okra. PKV Research Journal. 21: 146-148.

Kumar, V., Chandrashekar, K., Sidhu, O.P. (2006). Efficacy of karanjin and different extracts of Pongamia pinnata against selected insect pests. Journal of Entomological Research. 30: 103-108.

Lale. A. and Kulkarni, D.K. (2010). A mosquito repellent karanj kunapa from Pongamia pinnata. Asian Agri-history. 14: 207-211.

Mamun, M.S.A., Shahjahan, M., Ahmad, M. (2009). Laboratory evaluation of some indigenous plant extracts as toxicants against red flour beetle, Tribolium castaneum Herbst. Journal of the Bangladesh Agricultural University. 7: 1-5.

Meera, B., Kumar, S., Kalidhar, S.B. (2003). A review of the chemistry and biological activity of Pongamia pinnata. Journal of Medicinal and Aromatic Plant Science. 25: 441-465.

Nasrin, M., Amin, M.R., Miah, M.R.U., Afroz, M., Akanda, A.M., Miah, M.G., Suh, S.J. (2021). Management of insect and mite pests of chili using botanical and synthetic chemicals. Indian Journal of Agricultural Research. 55: 674-680.

Nguyen, T.H., Hoang, T.N.H., Ho, V.D., Tran, D.H., Bui, H.T. (2014). Furanoflavonoids from the plant Pongamia pinnata (L.) (Fabaceae) growing in the province of Thua Thien Hue, Central Vietnam. Farmaceutical Journal. 54: 42-46. (in Vietnamese with English summary).

Nguyen, T.M., Le, N.T.T., Havukanen, J., Hannaway, D.B. (2018). Pesticide use in vegetable production: A survey of Vietnamese farmers' knowledge. Plant Protection Science. 54: 203-214.
Poonia, S., Kaushik, R. (2013). Synergistic activity of a mixture of Pongamia pinnata (Karanj) and Kigelia africana (Sausage tree) leaf extracts against yellow fever mosquito, Aedes aegypti. Pakistan Entomologist. 35: 1-4.

Shoba, G.F. and Thomas, M. (2001). Study if antidiarrheal activity of four medicinal plants in castor-oil induced diarrhea. Journal of Ethnopharmacology. 76: 73-76.

Shunmugadevi, C. and Anbu Radhika, S. (2020). Bioactivity of plant extracts againts cowpea bruchid Callosobruchus maculatus (Fab): A review. Agricultural Reviews. 41: 185-200.

Sivapragasan, A. (2005). Development of cabbage webworm, Hellula undalis (Fabr.) on head cabbage, Brassica oleracea var. capitata. Journal of Tropical Agriculture and Food Science. 33: 321-331.

Sivapragasan, A. and Chua, T.H. (1997). Natural enemies for the cabbage webworm, Hellula undalis (Fab.) (Lepidoptera: Pyralidae) in Malaysia. Researches on Population Ecology. 39: 3-10.

Tran, D.H., Takagi, M., Takasu, K. (2004). Effects of selective insecticides on host searching and oviposition behavior of Neochrysocharis formosa (Westwood) (Hymenoptera: Eulophidae), a parasitoid of the American serpentine leafminer. Applied Entomology and Zoology. 39: 435-441.

Tran, D.H., Ueno, T. (2012). Toxicity of insecticides to Neochrysocharis okazakii, a parasitoid of Liriomyza leafminers on vegetables. Journal of the Faculty of Agriculture, Kyushu University. 57: 127-131.

Tran, D.H. and Nguyen, T.G. (2019). Development of the cabbage webworm, Hellula undalis (Fabricius) (Lepidoptera: Pyralidae) on different brassica cultivars in Central Vietnam. Research on Crop. 20: 798-801.

Tran, D.H., Le, K.P., Tran, H.D.T, Ueno, T. (2016). Control efficacy of pongam (Prongamia pinnata L.) leaf extract against the turnip aphis Lipaphis pseudobrassicae (Davis) (Heminoptera: Aphididae). Journal of the Faculty of Agriculture, Kyushu University. 61: 141-145.

Tran, D.H., Takagi, M., Ueno, T. (2017). Efficacy of the extract from pongam leaves (Pongamia pinnata L.) against Spodoptera exigua (Hubner) and Spodoptera litura Fabricius (Lepidoptera: Noctuidae). Journal of the Faculty of Agriculture, Kyushu University. 62: 439-443.

Tran, T.T., Le, V.V., Nguyen, L.H. (2018). Study on damage situation of the cabbage webworm, Hellula undalis Fabricius (Lepidoptera: Crambidae) on green mustards at the Mekong Delta. Can Tho University Journal of Science. 54: 115-124.

Verma, M., Pradhan, S., Sharma, S., Naik, S. N., Prasad, R. (2011). Efficacy of karajin and phorbol ester flaction against termites (Odontotermes obesus). International Biodeterioration and Biodegradation. 65: 877-882.

Waterhouse, P.H. and Norris, K.R. (1989). Hellula species. In: Biological Control: Pacific Prospects- Supplement 1. ACIAR Monograph No.12, pp. 76-87. 